\title{
Ontological approach to the formation of subject-oriented knowledge bases in the field of computer-aided design
}

\author{
Andrey Cherepashkov ${ }^{1, *}$ and Anastasia Sharaukhova ${ }^{1}$ \\ ${ }^{1}$ Samara State Technical University, Samara, Russian Federation,
}

\begin{abstract}
The problem of the formation of subject-oriented knowledge bases in the subject area of operation of computer-aided design systems is discussed. One of the trends in the development of CAD systems is their intellectualization through the development of a system-wide environment, including the means of methodological support of the design activities of users. It is proposed to use the otological approach in identifying and updating the content of knowledge bases used by target CAD personnel. The results of an experiment on the development of a targeted taxonomy in the subject area of computer-aided design of engineering products are presented.
\end{abstract}

\section{Introduction}

Currently, the creation of effective technical objects and structures in a timely manner and with the specified tactical and technical characteristics is not possible without the use of digital equipment and technologies. The main tools that provide computer support for creative engineering activities in the processes of developing new technology are computeraided design (CAD) systems. Modern CAD systems, along with the already traditional modules of geometric modeling, calculations, and design documentation, include intelligent information and consulting subsystems [8-10]. In addition to the operational presentation of reference technical information, intelligent subsystems can provide the formation and targeted use of knowledge bases (KB) that support human analysis and design decisions.

\section{Formation of the knowledge base of the CAD domain}

When forming a knowledge base, expert processing of large information arrays is most often used by groups of experienced designers who are narrow specialists in certain technical issues [11]. The use of an ontological approach is proposed to formalize and automate the procedures for expert filling of subject-oriented knowledge bases [12]. As a specific example, this article discusses the subject area of computer-aided design of engineering facilities. Currently, the world has accumulated an almost immense ocean of factual information on engineering design. In this article, in order to reasonably limit the

\footnotetext{
* Corresponding author: eg@samgtu.ru
} 
analyzed information arrays for the formation of subject-oriented knowledge bases, it is proposed to use well-known qualification descriptions and regulations used for the training and retraining of personnel in the field of automated learning. design. Along with educational rules and instructions, it is textbooks and teaching aids that contain in a concentrated and generalized form not only preliminary data that have passed the preliminary selection of experts from a specific subject area, but also a system of rules and relations that link them. The totality of the experimental approbation of methodological literature can rightfully be considered as the primary ontology $[4,6,7,12,14,15]$. As a rule, primary ontologies are poorly formalized, incomplete (and in some cases redundant), and contradictory. The use of the apparatus and tools of ontological analysis allows to a certain extent to streamline the information contained in the methodological literature, giving it a structured look, necessary for creating intelligent CAD information and consulting systems.

\section{Filling the CAD domain}

It should be noted that after the gradual and steady development of the global CAD industry, the content of the field of knowledge necessary for specialists working in the environment of automated life cycle management systems (LCI) of engineering objects, the so-called (PLM systems), is rapidly developing. Previously, each engineer involved in various stages of design work, manufacture and operation of engineering facilities, responded only to his field of activity. In the digital economy, a synthetic specialist with a system of interconnected knowledge at a number of stages of the life cycle will be in demand [3, 14].

For a generalized description of the area of competence of an effective CAD specialist, the following formula can be identified:

$$
K_{P L M}=K_{C A D} \cup K_{K P P} \cup K_{C A E} \cup K_{C A M} \cup K_{C A X}
$$

Where:

$\mathrm{K}_{\mathrm{CAD}}$ - many competencies related to CAD tools designed to automate two-dimensional and / or three-dimensional geometric design, create design and / or technological documentation, as well as general-purpose CAD.

$\mathrm{K}_{\text {CAPP }}$ - many competencies related to automation of technological process planning, used at the junction of CAD and CAM systems.

$\mathrm{K}_{\mathrm{CAE}}$ - many competencies related to automation tools for engineering calculations, analysis and simulation of physical processes, carry out dynamic modeling, verification and optimization of products.

$\mathrm{K}_{\mathrm{CAM}}$ - many competencies related to the means of technological preparation of the production of products providing automation of programming and control of equipment with CNC or GAPS.

$\mathrm{K}_{\mathrm{CAX}}$ - many promising and rare competencies related to the means of complex automation of various stages of the life cycle.

In the professional literature on CAD, the term CA " $x$ " is used to denote a constantly evolving set of promising technologies for industrial automation. For example, CAI, CAA, 
etc. Currently, in the general complex of basic CAD technologies, a new place is clearly visible for computer competencies related to additive technologies.

\section{Approaches in the description of the required competencies}

By academic definition, CAD is an organizational and technical system in which the leading place is given to project personnel equipped with a developed set of automation tools. CAD, in turn, is included in the integrated information and production environment of the enterprise, called the integrated information system (IMS)[5]. From the point of view of informatics, IMS can be considered as a multi-level subject-oriented information environment (Fig. 1), with areas corresponding to various types of personnel activities described in terms of professional competencies.

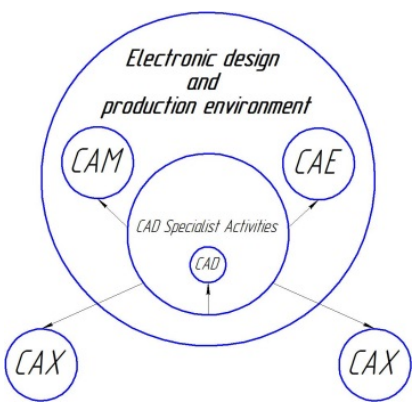

Fig. 1. Subject-oriented information environment

At the moment, there are a number of approaches that allow one way or another to describe the competencies necessary for CAD specialists. The most formalized concepts of competences of a specialist in the field of Mechanical Enquiring were worked out during the international and national competitions of professional excellence WorldSkills [13]. In these professional competitions, in addition to direct participants, a significant number of experts are foreseen. The need for objective grading and highlighting the winners of the competition led to the creation of a practically verified and unambiguous system for evaluating project activities in the environment of engineering CAD systems. In this case, certain criteria for evaluating design work are used. Amendments and corrections are regularly introduced into the assessment system and, accordingly, in determining the content of competencies of participants. Thus, it can be stated that at present, WorldSkills uses some of the most reliable methods for identifying and formalizing the content of competence components in the field of computer-aided design of engineering objects.

In the WorldSkills movement, the primary (root) competency is called the CAD Specialist. But such a generalized competence (as well as any complex system) must have certain components that, in terms of the ontological approach, are interconnected by certain goals and relationships. In the pedagogical sciences, it is customary to distinguish several types of components of educational competencies [16], including such as knowledge and skills.

\section{CAD Ontology}

It should be noted that in addition to professional knowledge and skills, a CAD specialist should have a set of reduced components that determine the cognitive and creative capabilities of the individual, called engineering abilities. The main task of compiling a detailed ontology of the subject area is to facilitate the CAD user to search for information 
in a large set of resources by systematizing knowledge, creating a single hierarchy of concepts, unifying terms and interpretation rules [1]. In addition, the Ontological approach will provide an opportunity for making scientifically based recommendations on targeted training and will be able to answer the question of what and in what sequence is better to study for the quickest solution to the problem.

In the field of computer-aided design (CAD) systems, there is a need to link the concepts of this subject area into a hierarchical structure with the aim of its conceptual description [2].

Computer-aided design is possible both individually, and teamwork on a complex project. This is where we will need an ontology with its constructed system of concepts, so that all members of the development team understand each other and use generally accepted common concepts.

\section{Development of a targeted approach to CAD}

The most interesting is the targeted approach to the creation and operation of computeraided design systems. Theoretically, the overall ontology of CAD is almost limitless, because every day there are more new elements of knowledge or questions (elements of not knowledge). In practice, a system of restrictions is always established, determined by the goals and objectives of a particular project or design direction. In this case, the target setting in the field of training and retraining of personnel for a particular enterprise can serve as a support for the development of ontologies of subject-oriented knowledge bases.

The ontological approach allows us to formalize a certain area of knowledge accumulated in science and practice in the form of a conceptual scheme. A schematically represented semantic network connects, according to certain rules, a system of concepts defined in a given subject area, including based on the terminology adopted there. In this case, a human-readable applied ontology is formed, as a rule, by experts, automated using special software tools (ontological editors), based on the subjective presentation of specialists about a specific subject area. Thus, the applied ontologies developed by experts are inherently incomplete and reflect particular aspects of the subject area selected for analysis. The target setting for creating ontologies seems very significant.

In the course of the study, it was proposed to divide the subject area of competence of a user of engineering CAD systems into 3 levels.

Table 1. Competency levels of a CAD specialist.

\begin{tabular}{|c|c|c|c|c|c|}
\hline \multicolumn{2}{|c|}{ 1st level } & \multicolumn{2}{|c|}{ 2nd level } & \multicolumn{2}{c|}{ 3rd level } \\
\hline $\begin{array}{c}\text { Computer } \\
\text { Graphics } \\
\text { Basics }\end{array}$ & $\begin{array}{c}\text { Computer } \\
\text { Graphics Basics }\end{array}$ & $\begin{array}{c}\text { Geometric } \\
\text { modeling }\end{array}$ & $\begin{array}{c}\text { Geometric } \\
\text { modeling }\end{array}$ & $\begin{array}{c}\text { Comprehensive } \\
\text { application of } \\
\text { CAD }\end{array}$ & $\begin{array}{c}\text { Comprehensive } \\
\text { application of } \\
\text { CAD }\end{array}$ \\
\hline $\begin{array}{c}\text { 2D } \\
\text { modeling }\end{array}$ & $\begin{array}{c}\text { Development } \\
\text { and execution of } \\
\text { electronic } \\
\text { documents }\end{array}$ & $\begin{array}{c}\text { Solid } \\
\text { modeling } \\
\text { Assembly }\end{array}$ & $\begin{array}{c}\text { Surface } \\
\text { modeling. } \\
\text { Kinematics }\end{array}$ & $\begin{array}{c}\text { Technological } \\
\text { modeling }\end{array}$ & $\begin{array}{c}\text { Reverse } \\
\text { engineering } \\
\text { Prototyping }\end{array}$ \\
\hline $\begin{array}{c}\text { CAD } \\
\text { WorldSkils }\end{array}$ & \multicolumn{2}{|c|}{ CAD +CAE } & CAD+CAE+CAM+CA'x' \\
\hline $\begin{array}{c}\text { Basic knowledge of } \\
\text { engineering and computer } \\
\text { graphics }\end{array}$ & \multicolumn{2}{|c|}{$\begin{array}{c}\text { Technology elements } \\
\text { Subject knowledge }\end{array}$} & \multicolumn{2}{|c|}{ Specialization } \\
\hline
\end{tabular}

This division into levels was achieved experimentally, which was tested at the university. These levels are based on the computer-aided design training system for many technical universities. 
An experiment was conducted to optimize the learning path. The first, considered option was classic, i.e. from initial knowledge and skills to the result.

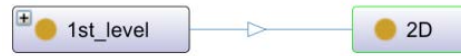

Fig. 2. Studying 2D modeling.

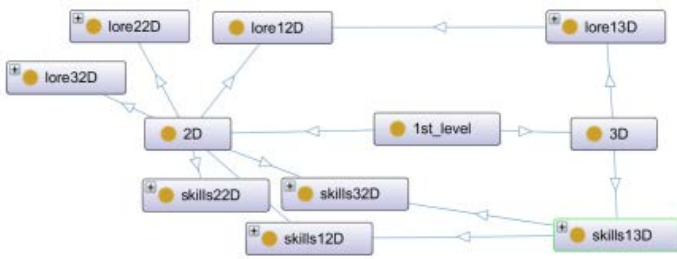

Fig. 3. Minimum knowledge and skills for 3D modeling

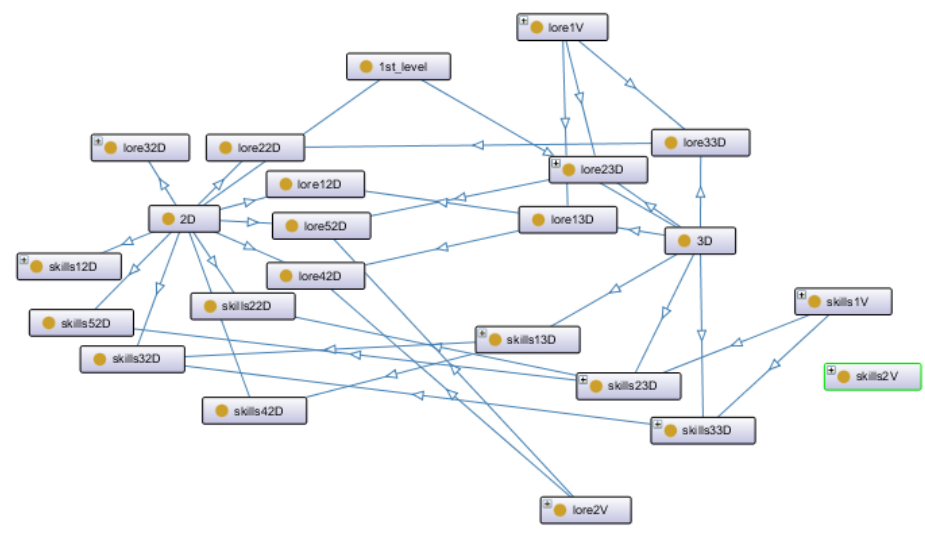

Fig. 4. Level 1 is mastered and initial knowledge of level 2 appears.

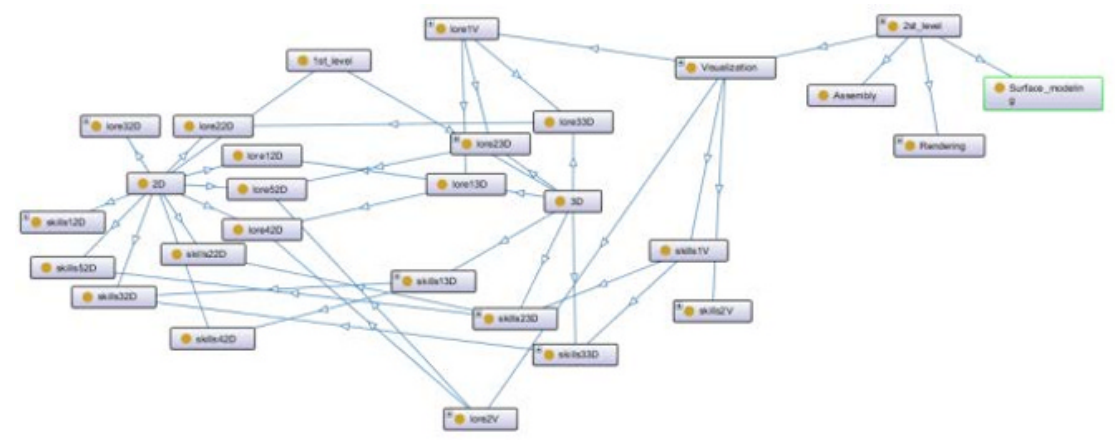

Fig. 5. Possible implementation of the elementary task of the 2nd level

Having built the entire CAD learning process using the ontological approach, the reverse methods managed to find the shortest path to the 3rd level and the minimum set of skills and knowledge for solving typical problems of this level. 


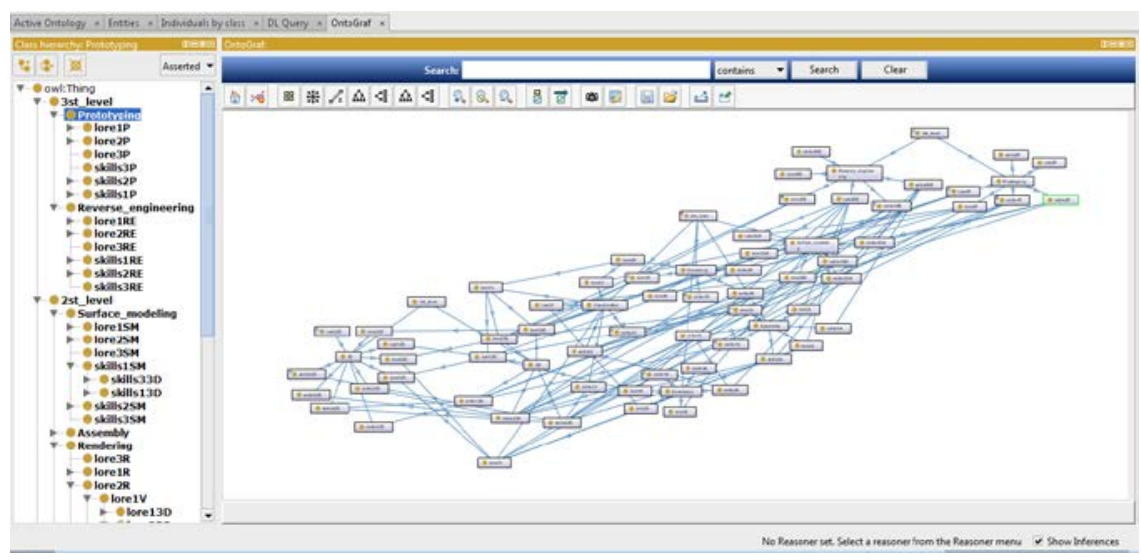

Fig. 6. CAD learning process in the program «proteg'e».

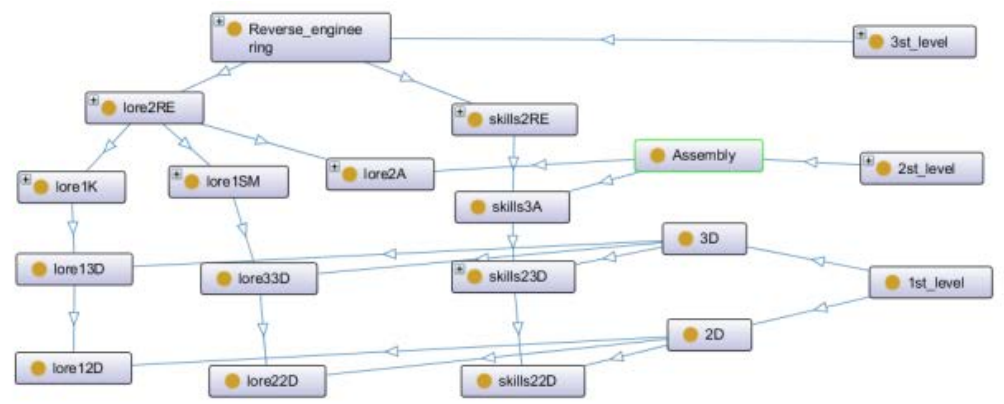

Fig. 7. The minimum set of knowledge and skills for solving elementary tasks of the 3rd level.

Having obtained this kind of result, we can conclude that the process of formation of target competencies can be significantly reduced both in time and in the amount of project data processed by the user. In the future, the formed "basic set of competencies" will be developed and replenished with the necessary knowledge and skills in accordance with the target settings already on the basis of the ontologically verified initial knowledge base.

\section{Conclusion}

The article proposes a new target methodology for the formation of a knowledge base of the subject area of computer-aided design systems. The objectives of ontanalysis are to identify the relevant set of competencies of students in CAD.

In the course of the experiment, a reverse method was used to select the knowledge and skill components of professional competencies with the properties and mechanisms for implementing training to achieve the goal.

In addition to the complex of professional knowledge and skills, a CAD specialist should have a definite path for the development of professional competencies, which varies depending on the complexity and direction of the project task. 


\section{References}

1. Guarino N. (Nicola) Formal ontology in information systems: proceedings of the first international conference (FOIS'98), June 6-8, Trento, Italy / N. (Nicola) Guarino, I. International Conference on Principles of Knowledge Representation and Reasoning (6th: 1998: Trento - IOS Press, 1998.-337c.

2. Ronconi G. The Mastro OBDA plug-in for Protégé / G. Ronconi, M. Ruzzi, V. Santarelli, DF Savo.

3. Andrei Aleksandrovich CherepashkovBasics of CAD in mechanical engineering: [textbook. allowance] - Andrei Alexandrovich Cherepashkov - Google Books / Andrei Alexandrovich Cherepashkov -, 2008. Issue. SamSTU - 130c.

4. Kozlov S.V. The use of ontologies in knowledge management systems of organizations / S.V. Kozlov, A.F. Tuzovsky, S.V. Chirikov, V.Z. Yampolsky - 2006.

5. Kulga KS Models and methods for creating an integrated information system for the automation of technical training and management of engineering production // - 2009.

6. Mitrofanova O.A. K.N.S. Ontologies As Storage Systems of Knowledge / K. N. S. Mitrofanova O.A.// All-Russian Competitive Selection of Survey and Analytical Articles According to the Priority Direction "Information and Telecommunication Systems" - 2008. - 54 p.

7. Education Automated methods for replenishing knowledge based on ontologies / U. V. Education.

8. NX [Electronic https://www.plm.automation.siemens.com/global/ru/products/nx/ 08/30/2019).

9. CATIA CAD 3D - Dasso Systems [Electronic resource]. URL: https://www.3ds.com/en/produkty-i-uslugi/catia/ (accessed: 08/30/2019).

10. Engineering Simulation \& amp; 3D Design Software |ANSYS [Electronic resource]. URL: https://www.ansys.com/ (accessed: 08/30/2019).

11. Tool system of computer-aided design SPRUT [Electronic resource]. URL: https://sprut.ru/products-and-solutions/products/sprut-tp/sprut (accessed: 08/30/2019).

12. Design ontology [Electronic resource]. URL: http://agora.guru.ru/display.php?conf=scientific_journal\&l=0 (accessed: 08/30/2019).

13. Home |WorldSkills Russia [Electronic resource]. URL: https://worldskills.ru/ (accessed date: 09/18/2019).

14. In Reply: BEHAVIOUR THERAPY / // Br. J. Psychiatry - 1966. - T. 112 - No. 483 211-212s.

15. Sources and sources of design ontology / - 2010.

16. Paley Elena Vadimovna PROBLEMS AND PROSPECTS FOR CONSTRUCTING ONTOLOGY OF EDUCATION / - 2014. - V. 12 - No. 50. 